\title{
Written in Blood? Decoding Some Red Inks of the Greek Magical Papyri
}

\author{
Miriam Blanco Cesteros
}

\begin{abstract}
In the procedures described within Greek magical papyri, it is common to find indications about the use of specific inks, usually characterized by the presence of peculiar substances. One such substance is blood, whose use is often interpreted in connection to the symbolic dimension of magic. A perusal of the relevant passages, however, reveals that some instances of "blood" have a different meaning. This paper analyses these formulas in the light of other sources in order to disclose the complicated network of Decknamen (code names) and to unveil the misunderstandings and erroneous inferences that have occurred in the course of their textual transmission.
\end{abstract}

\section{Keywords}

magic - inks - code names - papyri

Due to the large number of preserved magical texts and artefacts (amulets, lead tablets, ostraca, engraved gemstones, etc.), Greco-Roman Egypt offers one of the richest contexts for the study of the phenomenon of magic in Antiquity.* The significance of these documentary and archaeological witnesses lies in the

* This paper is part of the research project AlchemEast - Alchemy in the Making: From Ancient Babylonia via Graeco-Roman Egypt into the Byzantine, Syriac, and Arabic Traditions. The AlchemEast project has received funding from the European Research Council (ERC) under the European Union's HORIZON 2020 research and innovation program (G.A. 724914). I would like to thank Claudia Colini for providing me with some bibliography relevant to this paper, and also the other participants of the workshop Traces of Ink for their valuable suggestions that helped me improve my research on this topic. The last reviews of this contribution occurred after a change of academic affiliation to the Universidad Complutense Madrid. 
fact that they provide direct evidence of the practice of magic in this period. ${ }^{1}$ Among them, the so-called magical papyri stand out as the most important source of information. Modern scholars have classified under this name a very heterogeneous set of papyri, ${ }^{2}$ not only because they spread over a large chronological frame - from the 2nd/1st century вС to the 5th/6th AC - but also because of the language in which they are written (Greek, Demotic and Coptic) and the varied character of their contents. An additional factor of heterogeneity is their nature. On the one hand, there are testimonies of "applied magic": writings and objects produced in the context of a magical ritual (e.g., magical gems, amulets and binding spells ${ }^{3}$ written on papyri and lead tablets). On the other hand, there are texts intended to preserve and transmit the knowledge and practice of magic. Modern scholarship refers to these as magical handbooks because they contain collections of spells and magical practices described in varying degrees of detail.

The ritual instructions in many of these handbooks mention a large number of inks, sometimes even including specific indications for their preparation. These inks were used within the magical ritual to write the spell or a special formula, to draw the magical signs or the figures of the gods that should be depicted as part of the practice. When examining descriptions of their composition, a peculiar substance, frequently employed, stands out: blood. By

1 I will deploy the term "magic" and the adjective "magical" fully cognisant of the problems associated with them, merely as a conventional way to talk about a scattered body of artefacts, texts and practices, without prejudging its relationship with religion.

2 Leaving aside the individual editions of papyri with magical content, the first catalogue inventorying Greco-Egyptian magical papyri was by Karl Preisendanz (ed.), Papyri Graecae Magicae Die griechischen Zauberpapyri, 3 vols (Stuttgart: Teubner, 1928-1932), revised and republished by Albert Henrichs in 2 vols (Leipzig-Berlin: Teubner, 1973-1974). Hans Dieter Betz (ed.), The Greek Magical Papyri in Translation including the Demotic Spells (Chicago-London: University Chicago Press, 1986) offered an English translation that also included non-Greek parts - which were excluded from Preidendanz's edition — and new papyri. In the 1990s, Franco Maltomini and Robert W. Daniel (eds), Supplementum Magicum (Opladen: Westdeutscher Verlag, 1990-1991), edited two volumes of new materials. Since then, new texts are being regularly published by researchers. The magical texts collected by Preisendanz are usually cited using the abbreviation $P G M$, followed by the roman number referring to the papyrus position in that specific collection (e.g. $P G M \mathrm{~V}$ ). The texts edited in the Supplementum (abbreviated as $S M$ ) are referred to using roman numbers: e.g. $S M$ 41. PDM stands for Papyri Demoticae Magicae. Regarding the use of editorial symbols in the quoted texts: round brackets insert interpretative specifications; square brackets indicate a lacuna; and angular brackets signify an unintentional omission by the scribe. Unless differently indicated, the English translations are mine.

3 This spell typology, which has several names in Greco-Egyptian magic (katadesmos, katochos, $a g \bar{g} g \bar{e}$ ), served to restrain the will of divine and human beings in multiple contexts (erotic, judicial, agonistic contexts, etc.). 
analysing the complex transmission of the magical texts and their codification using Decknamen (code names) this paper explores the possibility that not all the substances used in the magical inks called "blood" were, in fact, blood.

\section{Understanding "Magical" Inks}

Before engaging with specific cases of magical inks, it is necessary to understand what the context in which they were employed was.

Briefly, in the 19th-century magic was considered typical of primitive societies and lower-classes, a practice precursor to religion and opposed to it. These formulations, however, have been superseded. In Antiquity, magic was a widespread phenomenon, whose practice did not know differences of gender, religion or social status. ${ }^{4}$ However, it is impossible to delineate a valid definition that may work both diachronically and synchronically, because its understanding varies significantly, depending on the point of view from which it is examined. ${ }^{5}$ Usually, the ritual and medical practices of a culture become "magical" when perceived from a different perspective. In regard to Greco-Roman culture, for example, an examination of the terms "magic" and "magical" reveals that they often simply meant "foreign, different from the rituals of the public cult of the polis/state," without implying that they actually were "magical" according to modern standards. Certainly, the problem is not less complicated in Egypt. The Egyptian word usually translated as "magic" (heka) was actually a broad concept intertwined with medicine and, above

4 See, for example, Daniel Ogden, "Binding Spells: Curse Tablets and Voodoo Dolls in the Greek and Roman Worlds" in Witchcraft and Magic in Europe: Ancient Greece and Rome, edited by Bengt Ankarloo, Stuart Clark (Philadelphia: University of Pennsylvania Press, 1999), pp. 54-70.

5 This topic, which is a compulsory subject for any analysis of ancient magic or magical texts, has been the object of much scholarly discussion. Fundamental studies in this regard include:Jan N. Bremmer, "The birth of term magic," Zeitschrift für Papyrologie und Epigraphik, 1999, 126:1-12 and "Appendix: Magic and Religion," in The Metamorphosis of Magic from Late Antiquity to the Early Modern Period, edited by Jan N. Bremmer, Jan R. Veenstra (Leuven-Paris: Peeters Publishers, 2002), pp. 265-269; José Luis Calvo Martínez, “¿Magos griegos o persas? Los usos más antiguos del término magos," $M H N H$ : revista internacional de investigación sobre magia y astrología antiguas, 2007, 7:301-314; Robert L. Fowler, "Greek Magic, Greek Religion," Illinois Classical Studies, 1995, 20:1-22; Fritz Graf, “Defining Magic — not Again?!” unpublished work whose draft is available at https://www.academia.edu/4054884/Graf Magic (last accessed 1o Dec. 2018); Bernd-Christian Otto, “Towards Historicizing 'Magic' in Antiquity," Numen, 2013, 6o:308-347; Henk S. Versnel, "Beyond cursing: the appeal to justice in judicial prayers," in Magika hiera. Ancient Greek Magic and Religion, edited by Christopher Faraone, Dirk Obbink (Oxford: Oxford University Press, 1991), pp. 6o-106. 
all, with religion. As a consequence, in the Egyptian socio-cultural context in which the Greek magical papyri were produced, these three fields were part of the same ritual reality and cannot be easily distinguished one from the other. ${ }^{6}$ These are some of the reasons why many rituals recorded in the magical papyri are similar to religious ones from a formal perspective. Accordingly, although its definition remains debated by specialists, modern scholars propose that ancient "magic" is just another form of expressing the human relation with the divine, located in the same continuum as "religion,"7 a field with which it was strongly interconnected.

Therefore, I will use the label "magical inks" to refer to those inks used in this particular context, although sometimes there is no difference between their composition and that of regular inks. In $P G M$ VII 226 , for instance, the

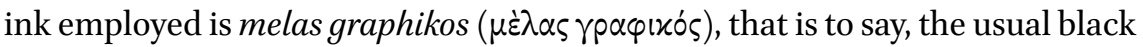
one. The majority of inks described in the Greek magical papyri, however, as produced in a ritual milieu with the purpose of functioning in a ritual context, are influenced by the performative nature of the magical procedure. This affects their composition, preparation and use.

Nowhere is this more evident than in ink recipes. Two kinds of components are fundamental to the composition of any ink: the pigment and the binder, which makes the ink adhere to the writing surface and guarantees the durability of the writing. Magical inks, however, can also contain peculiar components that do not make sense from a practical perspective. By contrast, their use can only be explained in terms of their symbolic value within a ritual framework: both the origin of these substances and the quantity in which they are employed respond to ritual requirements. This is the case, for example, with the " 7 wings of the Hermaic ibis," as we can read in the recipe below, which is used to write a formula to strengthen memory:

This is the preparation of the ink: myrrh troglitis, 4 drachmas, 3 Karian figs, 7 pits of Nikolaus dates, 7 dried pine cones, 7 piths of the single-stemmed wormwood, 7 wings of the Hermaic ibis (ibeōs Hermaikēs ptera, ‘ $\beta \varepsilon \omega \varsigma$

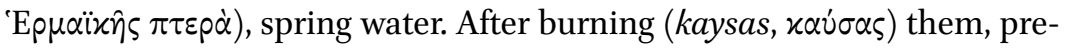
pare and write.

$P G M$ I $243-246$

6 See Geraldine Pinch, Magic in Ancient Egypt, 1st ed. 1994 (London: British Museum Press, 2010); Robert Kriech Ritner, The Mechanics of Ancient Egyptian Magical Practice, 1st ed. 1993 (Chicago-Illinois: Oriental Institute of the University of Chicago Press, 20o8), pp. $3^{-28}$, 235-249.

7 Christopher Faraone, "The agonistic context of early Greek binding spells," in Magika Hiera (cit. note 5), pp. 17-20. 
Without going into specifics, many cultures consider the number seven to be the bearer of a special symbolism because of different reasons (mythological causes, philosophical reinterpretations, religious beliefs, etc.). ${ }^{8}$ In Greco-Egyptian magic, its symbolism is bound to so many cultural inputs and systems of thought that it is difficult to know its meaning with any certainty, other than the general view that it was considered as a special and powerful number. As for the ingredient itself, the ibis was identified with the god Thoth, ${ }^{9}$ who, in turn, was associated with the Greek god Hermes. ${ }^{10}$ From this syncretism the god Hermes-Thoth emerges. Hence the ibis is given the adjective Hermaike ('Epuaïxn') in the recipe and, in the magical practice, this ink is called the "ink of Hermes" (1. 246). Regarding the connection between Thoth and Hermes and the ink, these "civilizer" gods were creators of different knowledge and learning. As a consequence, they were also considered as the gods presiding over memory, as can be evinced from some texts on Hermes.11 The inclusion in the recipe of a component associated with Hermes-Thoth established a sympathetic link between the divine power and the purpose of the formula - to improve memory — that guaranteed its efficacy.

From a merely technical point of view, this ink, prepared from the ashes of burned components, can be classified as a carbon ink, one of the oldest and most frequently used inks in Antiquity. ${ }^{12}$ However, in the strongly ritualized context of magical practice, it is difficult to distinguish the act of burning ink's ingredients from the burning of an offering. In fact, the verb employed to describe the burning of ink's ingredients in some recipes ${ }^{13}$ is epithyō ( $\dot{\varepsilon} \pi(\theta \dot{v} \omega)$, a verb from the ritual sphere that means "to burn as an offering, to make a burnt

8 See, e.g., Milena Bogdanović, “The number and its symbolism in ancient Greece," Journal of Arts and Humanities, 2013, II 6: 116-121 and Rodney Ast, Julia Lougovaya, "The Art of Isopsephism in the Greco-Roman world," in Ägytische Magie und ihre Umwelt, edited by Andrea Jördens (Wiesbaden: Harrassowitz, 2015), pp. 82-98.

9 See, e.g., Donald B. Redford, The Oxford Encyclopedia of Ancient Egypt, 3 vols (Oxford: Oxford University Press, 2001), s.v. "Thoth."

10 Garth Fowden, The Egyptian Hermes (Princeton: Princeton University Press, 1986), pp. 23-31.

11 See, e.g. h.Merc. 428-429; h.Orph. 28.12 and Call. Iambi, Fr.221 Pfeiffer.

12 See the summary, with specific bibliography, in Thomas Christiansen, "Manufacture of Black Ink in the Ancient Mediterranean," Bulletin of the American Society of Papyrologists, 2017, 54:167-195, pp. 171-175.

13 E.g. PGM IV 2205 and 2226. The preparation of the latter is disseminated among the instructions for a brief erotic practice. The recipe for this ink is thus difficult to distinguish at first sight. It is a kind of myrrh ink — the technical term in PGM is zmyrnomelan

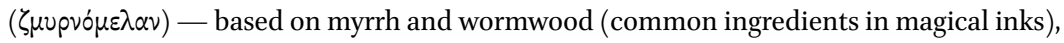
burned with sumac (a substance with high-tannic content employed in Antiquity to produce pigments) and roses. Since roses were considered a creation by Aphrodite, this last ingredient was probably a sympathetic one. 
offering." This suggests that this action could function simultaneously on both levels, i.e. the making of the ink and the magical ritual.

The special, ritual application of these inks also explains why an essential and functional - component of ordinary inks, i.e. the binder, is absent from many of them. ${ }^{14} \mathrm{~A}$ large number of magical inks were used to write texts that were meant to disappear (by the action of time, water, fire, etc.) rather than endure for a long time. This was also a simple way to ensure a practice was impossible to annul. In other cases, the ink acted as a vehicle for the magical properties of the formula, transferring them to the practitioner who had to lick the text or drink the water that had been used to wash the text. ${ }^{15}$ Since, in these cases, it was not intended for the pigments in these inks to adhere to the writing surface in a durable way, the binding agents were superfluous.

However, leaving aside the performative context, in terms of their technical characteristics, the procedure for the production of magical inks was no different from that used to make non-ritual inks: the ingredients were reduced into powder by burning or grinding and then mixed with a moistening agent in order to dissolve it or to create a suspension. Similarly, the majority of the ingredients used in magical inks (e.g. wormwood, pine cones, figs, myrrh, etc.) can be found in other ancient recipes for the preparation of inks, as Thomas Christiansen has recently demonstrated. ${ }^{16}$ According to Christiansen's research, all the inks of $P G M$ are classifiable within the three categories of inks known in Antiquity: ${ }^{17}$ the aforementioned carbon inks, iron gall inks ${ }^{18}$ and mixed inks. ${ }^{19}$ After these preliminary remarks, it can be stated that an ink is defined as "magical" by the context in which it was produced or used, rather than by any technical reasons related to its composition or preparation.

14 In fact, only one recipe ( $P G M$ XII 97-99, cited below) explicitly mentions gum arabic

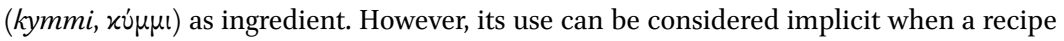
includes common black ink, e.g. $P G M$ VIII $69-73$.

15 See, e.g., $P G M$ I 232.

16 Christiansen, Manufacture (cit. note 12).

17 I follow the classification given in Christiansen, Manufacture (cit. note 12).

18 An ink made by adding some iron sulphate to a solution of tannic acid, a compound extracted from oak galls. The tannic acid reacts with iron salts producing a brown-black ink, see Christiansen, Manufacture (cit. note 12), p. 170 with specific bibliography.

19 Carbon inks that add metallic components to the mixture; in other cases, they are made from a suspension of some metallic powder in a binding substance, see Christiansen, Manufacture (cit. note 12), p. 17o. Such inks are also called compound inks. 
The expression "written in blood" becomes literal in Greco-Egyptian magic, which had a particular preference for red inks, the preparation of which sometimes included the use of blood as a peculiar and characterizing ingredient.

Whatever the culture, blood is a substance that has had and, indeed, continues to have an undeniable symbolic and spiritual value: no other substance has ever represented the power of life and death like blood. It is perhaps for this reason that ancient cultures actually had an ambivalent attitude towards it, considering blood to be simultaneously sacred and a bearer of danger and impurity. ${ }^{20}$ As a ritual sphere, Greco-Egyptian magic also shared this dual approach to the vital humor: on the one hand, blood was employed as an offering for the gods as well as for consecrating objects; ${ }^{21}$ on the other, the spilling of different kinds of blood was denounced as a crime in magical practices. ${ }^{22}$ Its main use, however, was as an ingredient for ink (see Table 2.1).

We should note that, in Antiquity, the use of blood as (or in) ink was neither restricted to magic, nor was it necessarily related to ritual purposes. Firstly, blood was the simplest and most immediate way to obtain a red substance to write with. On the other hand, different sources inform us about the use of blood as (or mixed with) ink in non-magical texts. ${ }^{23}$ When used in iron gall inks, for instance, its use is entirely practical: the high iron content of the blood

20 Regarding ancient Greece, for example, animal blood was poured onto the altars during blood sacrifices; purification by blood was considered among the most effective rituals of this kind, see Robert Parker, Miasma: Pollution and Purification in Early Greek Religion, (Oxford: Oxford University Press, 1983), p. 23o. But while the blood cleaned and released worshippers from their sins, its spilling implied a murder, which tainted whoever committed it (ibid., pp. 104-143). In fact, any bloodshed was dangerous, likewise life events linked to blood, such as childbirth and menstruation (ibid., pp. 270-273).

21 E.g. on blood used for consecrating the space and objects for the magical practice, see PGM II 160; IV 2888; VII 868; XXXVI 233; on blood used as offering, see, e.g. PGM II 177 and IV 2883 .

22 The context of these denunciations is always a ritual diabole (slander spell) in which the magician denounces the actions and words of someone to the gods in order to ensure a divine punishment for this person. Such actions, however, were not committed by the denounced persons (for this reason it is slander). By contrast, some of the practices reveal that the denunciations were actually done by ritual practitioners, who later attributed them to the victim of the spell. These are, e.g. a goat's sacrifice in PGM IV 2575 (=IV 2643), done by the magician at l. 2685; the spilling of donkey's blood in PDM xiv, done by the magician at ll. 679-681.

23 See, e.g. the manuscript studied by Marina Bicchieri and Flavia Pinzari, "Discoveries and oddities in library materials," Microchemical Journal, 2016, 124:271-273. 
TABLE 2.1 Blood as an ingredient of ink and other uses in Greco-Egyptian magical texts

\begin{tabular}{|c|c|c|}
\hline Ink & 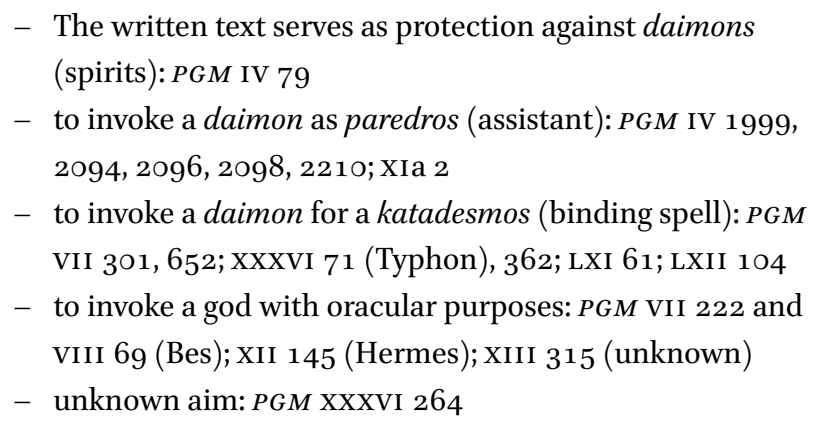 & $60 \%$ \\
\hline ther uses & $\begin{array}{l}\text { II 16o, 177; IV 41, 2883, 2888, 3257; V 2666; VII 868; XIb 4; } \\
\text { XXXVI 233; SM 10oa, l. } 4\end{array}$ & $36,6 \%$ \\
\hline bious & $P G M$ III $410^{\mathrm{a}}$ & $3,3 \%$ \\
\hline
\end{tabular}

a The text is very lacunose, but as it is immediately followed by the indication "write with a pen," this blood was probably used as ink or ink component.

reacts with tannic acid, darkening the ink. ${ }^{24}$ This same chemical reaction is also behind the utilization of blood for invisible inks: ${ }^{25}$ texts written using diluted blood could be revealed as a result of the chemical interaction with other substances like the aforementioned tannic acid.

Another interesting point that emerges from the table above is the strong connection of inks made with blood to harmful magic and, in general, the demonic world. This specialization could be due to its colour. Indeed, in ancient Egyptian culture red was a powerful and ambivalent colour associated with many things that were considered both positive and dangerous (like, e.g., fire or blood itself). Its negative overtones seem to originate from its association with the desert and its sovereign, the god Seth. Consequently, this colour assumed the negative ideas that the desert and Seth personified, including the notions of "evil," 26 chaos, hostility, disorder, violence and pain. ${ }^{27}$ As a result,

24 As proven by laboratory replication, cf. Bicchieri, Pinzari, Discoveries (cit. in the previous note), p. 272.

25 Such use is mentioned regarding early Medieval Jewish handbooks, by Martin Levey, "Some Black Inks in Early Mediaeval Jewish Literature," Chymia 1964, 9:27-31, p. 28.

26 Ritner, Mechanics (cit. note 6), p. 147, n. 662.

27 See Herman T. Velde, Seth, God of confusion (Leiden: Brill, 1967), pp. 81ss.; Redford, The Oxford Encyclopedia (cit. note 9), p. 269, s.v. Seth; Pinch, Magic (cit. note 6), pp. 191-194, s.v. Seth. The basic word for red, $d \grave{s} r$, was closely connected with that of anger and fury, both ideas also personified by Seth, see Geraldine Pinch "Red things: the symbolism of colour 
red was associated with demonic figures and hostile gods; ${ }^{28}$ it was also used for writing the names of such divinities and enemies, while red rubrics were avoided for other gods. ${ }^{29}$ Therefore, considering the Egyptian background of the magical papyri, the use of red inks in aggressive magic and in the invocation of Underworld entities, such as spirits of the dead, does not seem arbitrary. Despite this, as stressed by Geraldine Pinch, "red things were dangerous, but they might, if handled in the right way, provide the most powerful protection available, ${ }^{\prime 30}$ so red could be also employed as an effective defense against any threat.

In my opinion, however, the symbolic and ritual dimension of the magical papyri has conditioned the interpretation of blood in magical inks. Modern studies about the inks described in Greco-Egyptian magical handbooks limit any consideration of blood to it being a ritual component. Consequently, the presence of blood in these texts has not received the attention it deserves: its presence is always explained - quite superficially — by the magician's wish to ensure the efficaciousness of the spell. ${ }^{31}$ Without excluding the actual use of blood in Greco-Egyptian magical rituals, the passages discussed below will evince that some mentions of animal bloods in ink recipes from Greco-Egyptian magical texts could actually be concealing the existence of completely different substances.

\section{3}

\section{Snake Blood}

The first case study concerns a substance called haima drakonteion ( $\alpha i \mu \alpha \delta \rho \alpha-$

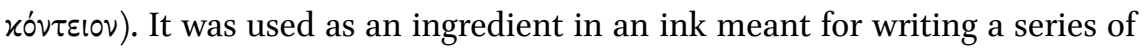
nomina magica in a procedure intended to conjure the spirit of a dead person as paredros (assistant). The recipe is as follows:

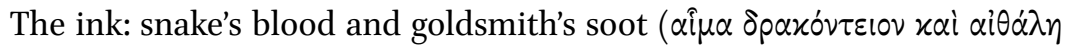

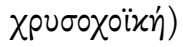

$P G M$ IV 1999

in magic," in Colour and Painting in Ancient Egypt, edited by W. Vivian Davies (London: British Museum Press, 2001), p. 184.

28 Ritner, Mechanics (cit. note 6), p. 147-148, especially note n. 662 and 663.

29 Ibid., p. 147, note n. 663 with specialized bibliography.

$30 \quad$ Pinch, Red things (cit. note 27), p. 184.

31 See, e.g. Christiansen, Manufacture (cit. note 12), p. 18 o. 


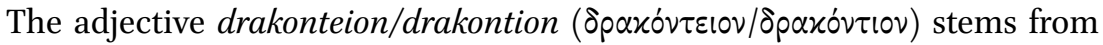
drakōn ( $\delta \rho \alpha \dot{x} \omega \nu$, a kind of snake), meaning "of/from the drakōn snake" or, in a more general way, "of/from the snake," so haima drakonteion is, literally, "snake blood."32 Several ancient sources, however, inform us that, despite its name, this was a vegetal substance. One of these sources is the Cyranides (1st/2nd century AD), ${ }^{33}$ a six-book treatise on the magical and medicinal properties of animals, plants and stones. In a passage entitled "the correct identification of the Snake-Plant, the Woodpecker Bird, the Dragon-Fish and

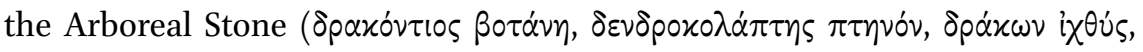
$\left.\delta \varepsilon v \delta \rho i \tau n \varsigma \lambda i \theta_{\circ \varsigma} \varepsilon u ̈ \gamma v \omega \sigma \tau \circ \varsigma\right)$ " this treatise states:

From the squashed seeds of this plant [i.e. the Snake-Plant], [a substance] is obtained that is called "snake blood" because it is red.

Cyran. 1.4.8 Kaimakis

The physician Aetius of Amida (5th/6th century AD) concurs with the Cyranides and, without specifying the part of the plant from which it originates, repeats that the snake blood is produced "by the Snake-Plant in the Indian lands" (Aët. $\mathrm{XV}, 13.141$ Zervos). In fact, even today, "dragon's blood" is the common name of a bright red resin exuded by different kinds of plants such as the Dracaena cinnabari.

On the other hand, it should be noted that both Aetius and the Cyranides explain what snake blood was; this suggests that the name of this substance probably led to confusion and that untrained people required clarification about the real nature of this substance. In this regard, Pliny the Elder (23-79 AD) is perhaps one of the most interesting witnesses to the ancient misinterpretation of what the snake blood was:

The Greeks give also to minium (i.e. the cinnabar, in lat. minium) the name of cinnabaris; a mistake is made because of this Indian name, for they give this name to the blood of a snake (saniem draconis) crushed

32 On the term drakōn, its meaning in Antiquity and for a general overview of its semantic evolution, see Daniel Ogden, Drakon: Dragon Myth and Serpent Cult in the Greek and Roman Worlds, (Oxford: OUP 2013), pp. 2-5. On the substance called haima drakonteion, with special attention to its botanical identification and the analysis of the sources, see Jean Trinquier, “Cinnabaris et 'sang-dragon': le 'cinabre' des anciens entre minéral, végétal et animal," Revue archéologique, 2013, 56:305-346.

33 On the complex tradition of this treatise and the discussion about its dating, see David

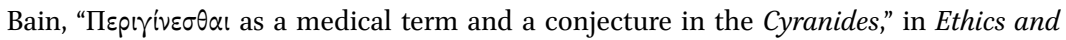
Rhetoric: Classical Essays for Donald Russell edited by Doreen Innes, Harry Hine et al. (Oxford: Clarendon Press, 1995), pp. 281-286. 
by the weight of dying elephants, which die mixing their blood with the blood of those animals - as we said - and there is no other colour that represents the blood in paintings more adequately.

PLIN., nat. XXXIII, $116^{34}$

Pliny's explanation (most thoroughly referred in Nat., VIII 12) surely is a popular belief originated from the literal interpretation of the expression haima drakonteion, which Pliny translates as saniem draconis. On the other hand, Pliny's account is interesting because it mentions a terminological misunderstanding between two red substances: namely, snake blood and cinnabar (HgS).

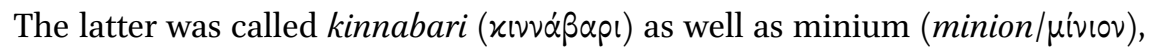
but certain literary sources, like the Periplus Maris Erythraei $\$ 30$ (ca. 4o/7o d.C.), evince that the snake blood in Antiquity was also called "(Indian) cinnabar." This led to the confusion between the two substances, as the Greek physician Dioscorides (c. 40-c. 9o AD) also discusses in Dsc. V $94 .{ }^{35}$ In this passage, in fact, the author distinguishes between minion (with which he refers to cinnabar) and the cinnabari, which is, according to him, a very rare Libyan substance that he describes as follows:

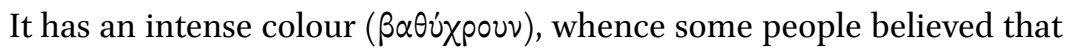

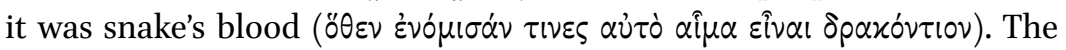
cinnabari has the same properties as the hematite; it is particularly suitable for ophthalmic remedies ...

DSC. V 94

Although the text is ambiguous with respect to its formulation, two reasons lead me to consider that Dioscorides is here reflecting the same popular misinterpretation as Pliny and, therefore, in this passage, haima drakonteion should be taken to be the actual blood of a snake. ${ }^{36}$ Firstly, Dioscorides talks about an erroneous popular belief (enomisan tines, he says); secondly, and most importantly, Dioscorides appears not to know of the vegetal substance called

34 Translation by Matteo Martelli, "Properties and classification of mercury between natural philosophy, medicine and alchemy," AION (Philol.), 2014, 36:17-48, p. 40. This translation follows the Latin edition by Zehnacker, Hubert, Pline l'ancien: Histoire naturelle, livre XXXIII (Paris: Les Belles Lettres, 1983).

35 About the confused and misleading terminology using in Antiquity for both the snake blood and cinnabar, as well as on a detailed analysis of the Pliny's and Dioscorides' texts here quoted, see Martelli, Properties (cit. note 34), pp. 39-44 and Trinquier, Cinnabaris (cit. note 32), 305-320.

36 For a radically different interpretation, see Pietro-Andrea Mattioli, I Discorsi nei sei libri di Pedacio Dioscoride Anazarbeo della materia medicinale (Venezia, 1568), pp. 1415-1416. 
snake blood, since this is the only mention in his work. In any case, Dioscorides' quotation confirms that, in Antiquity, there was a certain confusion regarding the denomination and identification of several red pigments, a phenomenon undoubtedly underpinned by its chromatic character. ${ }^{37}$ In fact, two recipes transmitted in alchemical treatises support that snake blood was used as a pigment, as Pliny says.

The first is a procedure for producing a red gemstone, ${ }^{38}$ preserved in the Stockholm Papyrus, a Greco-Egyptian alchemical handbook (4th century ca.) written by a scribe who also produced an important magical handbook (PGM XIII). The second, although transmitted by a later alchemical treatise - the Mappae clavicula (henceforth $M c$ ) — provides the most meaningful evidence for the interpretation of the recipe from $P G M$ IV 1999 (the magical ink with which we began this analysis). The Latin alchemical recipe book, compiled circa the 8th century, probably originated from a lost Greek original that collected a tradition of recipes very close to that of the Stockholm Papyrus; that is to say, another Greco-Egyptian treatise from roughly the same period. ${ }^{39}$ This is the recipe:

Add Indian snake blood to the gold (sanguine draconis indici inunge aurum) and put them in a copper container. Place charcoal around it and leave it there until they [i.e. the two aforementioned substances] melt and it [i.e. the mixture] is so liquefied that you can write with it.

MC XLV

I want to stress the similarity between the ingredients employed in this ink - snake blood and gold - and those of the magical ink — snake blood

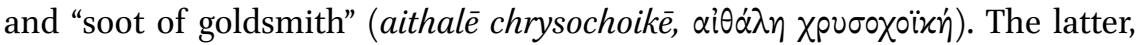
however, is difficult to interpret. Aithale $(\alpha i \theta \dot{\lambda} \lambda \eta)$ commonly means "soot, thick smoke." 40 This term was used, in natural philosophy and medicine, to describe

37 Note that echoes of such identification remain in the botanical name of the tree Dracaena cinnabari.

$38 \quad$ P.Holm. $\$ 62(1.422)$.

39 The numerous Graecisms of the oldest versions prove the dependence of the Mappae clavicula on a Greek source. Although this Greek model has some recipes in common with P.Holm. and its brother-treatise, the P.Leid. $x$, it has recently been argued that the MC's source was not a compendium derived from P.Holm. and P.Leid. $x$, but rather a contemporaneous treatise belonging to the same alchemical tradition, see Gaia Caprotti, "Mappae clavicula: prescrizioni della prima alchimia storica nei precedent di lingua greca," in Mappae clavicula. Alle origini dell'alchimia in Occidente edited by Sandro Baroni et al. (Milano: il Prato, 2013), p. 219.

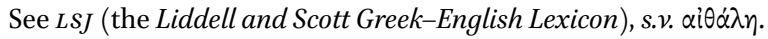


substances that condense in a solid form (i.e., as a soot) during (or as a result of) the treatment of some ores. ${ }^{41}$ Yet, no derivative is obtained when gold is heated. Given the parallels with $M c$ 's recipe, however, we cannot rule out that the "soot of goldsmith" from the magical ink was simply gold or some kind of golden blend described in a technical or, more probably, hermetic way. ${ }^{42}$ If so, both the magical and the alchemical recipe would simply employ a red resin with gold.

Other possibilities emerge, however, from another passage from the magical papyri: $P G M$ XII 410. This text once again features the three ideas just discussed - i.e. the misleading nature of the name of this substance; the misinterpretations that this caused; and the confusion of snake blood with other red minerals for chromatic reasons:

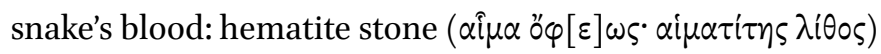

This quotation belongs to a list - to which I shall return in a moment of alleged Decknamen (code names) used by magicians to conceal the real name of the substances used in their rituals. A quick glance at any dictionary reveals that this haima opheōs ( $\alpha \hat{i} \mu \alpha$ ö $\varphi \varepsilon \omega \varsigma$ ) is our haima drakonteion ( $\alpha i \mu \alpha \delta \rho \alpha$ -

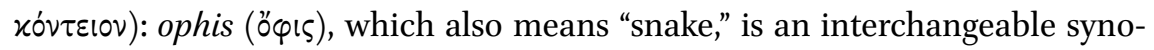
nym for drakōn $(\delta \rho \alpha \dot{\alpha} \omega \nu)^{43}$ that has replaced drakonteion here. In this context, drakonteion is a botanical name that refers to the 'snake-plant.' Its replacement with opheōs ("of snake") transforms the phrase haima drakonteion (i.e. a red substance that comes from the 'snake-plant') into real and literal snake blood. Since this is a list of equivalences (see below), it implies also that the magician considered snake blood a name for hematite. This stone, whose name stems from the Greek word haima ( $\alpha i \mu \alpha$, "blood") due to its coloration, ${ }^{44}$ was also mentioned by Dioscorides in the passage quoted above because of its similarity with snake blood. ${ }^{45}$ The magical text thus proves that snake blood and hematite could be erroneously identified as a single substance.

41 E.g., mercury obtained from cinnabar, or cadmia from copper, see Martelli, Properties (cit. note 34$)$, pp. $27-32$.

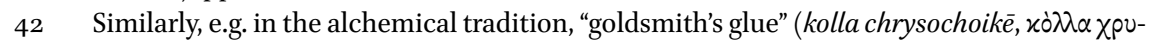

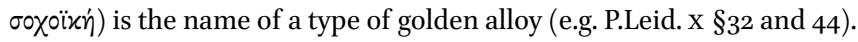

43 See $L S J$, s.v. $\delta \rho \alpha \dot{\alpha} \omega \nu$.

44 I agree with Caley-Richards that, when ancient authors talk about the hematite like a bright red gemstone, they did not mean the metallic gray mineral known until today as hematite, see Earle R. Caley, John F.C. Richards, Theophrastus, De Lapidibus/Theophrastus, On Stones (Ohio: Ohio State University Press, 1956, repr. 2016) pp. 138-139. See also George Rapp, Archaeomineralogy (Berlin-Heidelberg: Springer Verlag, 2009), pp. 113-114.

See above. See also note 35 for bibliography. 
This distortion of both the common technical name and the real nature of the substance illustrates the kind of changes and alterations that technical terms could experience in the context of fluid traditions, like the one that characterized ancient recipes.

\section{$4 \quad$ Blood of Donkey/Typhon}

The second case of inquiry, while different, illustrates similar phenomena. It is the "blood of donkey," a substance employed for writing (as ink or mixed with other ingredients to make an ink) and mentioned in the following passages from $P G M$ :

[a.] Take the blood of a black ox or of a goat or of Typhon - but preferably from a goat - and write.

$P G M$ VII $65^{2}$

[b.] Formula written on a little piece of papyrus using Typhon's blood. $P G M$ LXI 61

The donkey, when mentioned in connection to Egyptian culture, evokes an immediate association with the god Seth. ${ }^{46}$ It was, in fact, one of the possible theriomorphic manifestations of this god. From the Hellenistic period, however, when Seth syncretized with the Greek monster Typhon, ${ }^{47}$ the latter also assumed the attributes and forms of Seth, to the point that in Greek magical papyri the nouns "donkey" and "Typhon" are interchangeable. ${ }^{48}$ Consequently, in Greco-Egyptian magic, we can consider the "blood of Typhon" (haima

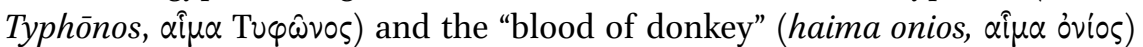
to be the same substance. Accordingly, three more inks can be added to those mentioned above:

[c.] Taking a piece of pure ( $\kappa \alpha \theta \alpha$ póv, new?) papyrus write the following names with donkey blood ( $\alpha i \mu \alpha \tau \iota$ òvi $\omega)$.

$P G M$ XXXVI 71

46 Redford, The Oxford Encyclopedia (cit. note 9), p. 270.

$47 \quad$ Pinch, Magic (cit. note 6), pp. 193-194.

48 The equation donkey-Typhon is especially clear in $P G M$ XI 2, which prescribes the use of a skull "of Typhon," clearly a donkey's skull. See also PDM XIV 675-694 (commented below and cited also above, in note 22). 
[d.] Taking a seashell, write (on it) the sacred names with the blood of a

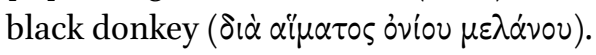

$P G M$ VII 300

[e.] The hide is written using blood from the heart of a slaughtered don-

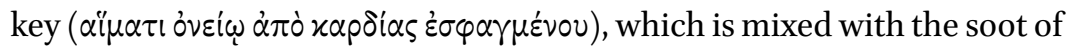
coppersmith ( $\alpha i \theta \dot{\alpha} \lambda \eta \chi \alpha \lambda \chi \dot{\varepsilon} \omega \varsigma)$.

$P G M$ IV $2093^{49}$

Unlike snake blood, which can quite safely be identified with a common botanical name, the substance called "blood of Typhon" or "blood of donkey" - at least at first sight - was the blood of this particular animal. This is evinced from, for example, the practice described in $P D M$ xiv $675^{-694}$, in which the magician announces to the gods that certain people must be punished because they have "spilled the blood of Typhon in their houses" (1. 692). This assertion is equated with the magician's ritual of anointing his hands with donkey blood (1. 680)..$^{50}$ The "blood of Typhon" could also refer to real blood in a passage like the example (a), in which the blood of other animals is given as an alternative. However, one of the magical inks listed above leaves some room for doubt about the general assumption that the "blood of Typhon" is always the blood of a donkey. It is the example (b) in which the "blood of Typhon" is glossed:51

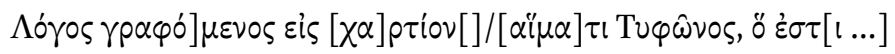

Formula written] on a little piece of papyrus using blood of Typhon, which is $[\ldots]$

In the context of Greco-Egyptian magic, where the identification between Typhon-Seth and the donkey was so strong that their names are interchangeable, a gloss specifying what "blood of Typhon" was would have made no sense unless there were other substances also bearing this name. Unfortunately, the second element of the equation has been lost.

In the flexible system of ancient Greco-Egyptian magic, it is difficult to know what these other substances would have been, but there are several

49 I will return to this recipe.

$5^{\circ}$ On this form of curse, see n. 22, above.

51 Other passages in which a gloss is introduced use the formula ho estin $\mathrm{x}$ ( 0 ह $\check{\sigma \tau \imath \nu}$..., "which is ..."), see, e.g. PGM III 425 and XIII 128. It must not be mixed up with the use of this same phrase to introduce ritual identifications. 
candidates. One could be, for example, wine. Plutarch (de Iside 6) reports that the Egyptians did not drink wine or use it as an offering because grape juice was considered "the blood of those who once were enemies of the gods" ( $\dot{\omega} \varsigma$

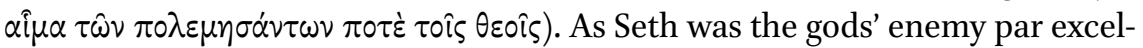
lence, some scholars identify the "blood of Seth" mentioned in some Egyptian rituals with wine..$^{52}$ The same is true of water from the Nile. ${ }^{53}$ However, to my knowledge, neither wine, nor Nile water were used to write Greco-Egyptian magical texts.

There was a second substance associated with Typhon-Seth, much less peculiar than the donkey's blood, but also of red colour and commonly employed as a pigment: minium ("red lead" or lead tetroxide; ${ }^{4}$ called miltos — $\mu^{\prime} \lambda \tau$ Tos — in Greek). ${ }^{55}$ In fact, miltos is mentioned among the ingredients of some magical inks:

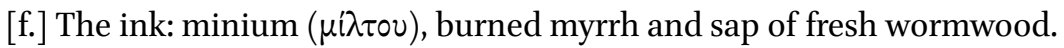
PGM IV 2153

[g.] [Write] with myrrh spiced with minium $(\mu i \lambda \tau \omega)$ on leaves of hellebore. $P G M$ XIXb 2

[h.] Take minium [and the blood] ${ }^{56}$ of a white dove $(\lambda \alpha \beta \dot{\omega} v \mu$ iो $\lambda \tau o v\langle x \alpha i$ $\alpha i \mu \alpha\rangle \pi \varepsilon \rho ı \tau \varepsilon \rho \hat{\varsigma} \varsigma \lambda \varepsilon \cup \kappa \hat{\eta} \varsigma)$ or of a crow, as well as the 'milk' of the sycamore,

52 See Dierk Wortmann, "Das Blut des Seth," Zeitschrift für Papyrologie und Epigraphik, 1968, 2: 227-23o.

53 Ibid.

54 According to the aforementioned texts of Dioscorides and Pliny (see $\S 3$, above), in Antiquity this mineral was commonly confused with other red pigments, such as cinnabar and iron oxides like hematite (red ochre). See also Rapp, Archaeomineralogy (cit. note 44), pp. 210 and 214.

55 See Rapp, Archaeomineralogy (cit. note 44), p. 214.

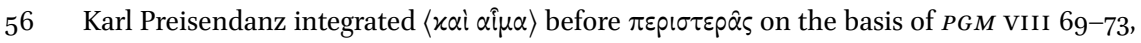
which transmits an alternative version of this magical procedure: "This is the ink with which you draw: blood of a crow, blood of a white dove ( $\alpha i \mu \alpha \pi \varepsilon p ı \tau \tau \varepsilon \rho \hat{\varsigma} \lambda \varepsilon \cup \cup \hat{\eta} \varsigma)$, lumps of incense, (etc.)." One could argue that this second version does not include minium, so $\mu$ í $\lambda$ $\tau 0 \nu \pi \varepsilon p i \sigma \tau \varepsilon \rho \hat{\varsigma} \varsigma \lambda \varepsilon \cup x \hat{\eta} \varsigma$ (in $P G M$ VII) could be replacing $\alpha \hat{i} \mu \alpha \pi \varepsilon p ı \tau \varepsilon \rho \hat{\varsigma} \varsigma \lambda \varepsilon u x \hat{\varsigma} \varsigma$ (miltos, thus, would mean in this case "blood"). Some translators, in fact, reject Preisendanz's integration and interpret miltos in this way, see note 59 below. As it will be shown later, the minium could ritually replace the blood of a donkey in some Typhonian contexts. However, in order to create such a metaphor (using term miltos for the word haima, "blood," even when not related to Typhonian animals), the ritual substitution should have been much more frequent. Yet, the true is that, for now, it is attested only in one case. 
sap of single-stemmed wormwood, cinnabar, and rainwater; blend, put aside and write with it.

$P G M$ VII 222-226

The use of minium for writing, though, was not restricted to magic: according to the results of modern chemical analysis, it is, indeed, one of the commonest substances used in the red inks of Greco-Roman Egypt. ${ }^{57}$ In Greco-Egyptian magic, however, it acquired a particular Sethian meaning, ${ }^{58}$ surely due to its red colour, as proved, for instance, by passages in which the minium is called

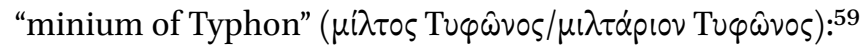

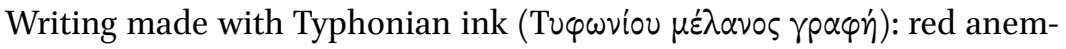
one, juice from an artichoke, seed of the Egyptian acacia, Typhonian min-

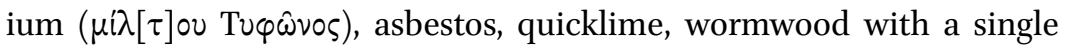
stem, gum arabic, rainwater.

PGM XII 97-99

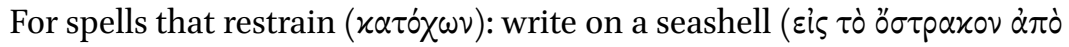
$\theta \alpha \lambda \alpha \dot{\sigma} \sigma \eta \varsigma)$ with the ink mentioned below (i.e. the myrrh ink described

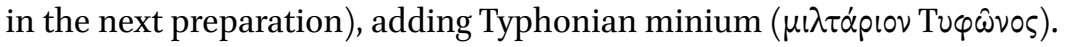

$P G M$ IV 2211-2215

Several recipes for red inks transmitted in medieval Arabic treatises include red anemone ( $\left.\dot{\alpha} v \varepsilon \mu \omega^{\prime} \nu \eta\right)$ as the main ingredient, which does not prevent this flower from being "regarded as containing the concentrate essence of redness." ${ }^{60}$ As

57 See Christiansen et al., "Chemical characterization of black and red inks inscribed on ancient Egyptian papyri: The Tebtunis temple library," in Journal of Archaeological Science: Reports, 2017, 14:208-219 and pp. 216-217.

$5^{8}$ The negative, Sethian connotations of the colour red - undoubtedly inherited from the Egyptian context - could explain, e.g. that certain practices stated the use of lamps "without minium" (amiltōton, $\dot{\alpha} \mu$ í $\tau \omega \tau \tau$ ) $)$ in order to avoid the dangerous influence of this colour on the ritual. For a complete list of texts, see Betz, Magical Papyri (cit. note 2), p. 336.

59 Miltarion ( $\mu \iota \lambda \tau \dot{\alpha}$ piov) is a diminutive of miltos, which here can be interpreted as a mere

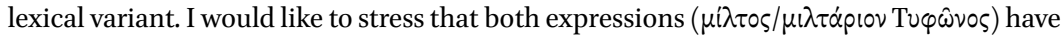
been interpreted in the quoted texts by some translators as "blood of Typhon," see Betz, Magical Papyri (cit. note 2), p. 77; and Luis Muñoz Delgado, Léxico de magia y religión en los

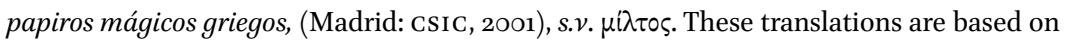
$P G M$ VII 222, which is interpreted according the papyrus' reading without Preisendanz's integration (see note 56 , above).

6o Pinch, Red things (cit. note 27), p. 183. The mentioned recipes are transmitted in the Zinat al-kataba (d. 925) by Abū Bakr Muḥammad ibn Zakariyyā’ al-Rāzī; Kitāb al-azhārfì 'amal 
far as minium is concerned, it developed a dual role as pigment and sympathetic ingredient. Therefore, both ingredients link the ink to the Sethian sphere by means of the colour. This is the reason, for instance, why the former ink is called "Typhonian."

Although minium is never called "blood of Typhon" in $P G M$, its red colour makes this equation likely. In fact, $P G M$ VII $300-302-$ a parallel version of $P G M$ IV 2211-2215 — ${ }^{61}$ demonstrates that, from a ritual perspective, minium and donkey's blood were commutable substances. Accordingly, this practice prescribes donkey blood instead of minium:

A restraining procedure ( $\dot{\alpha} \gamma \dot{\omega} \gamma(\mu \circ v)$ that acts within an hour: take a sea-

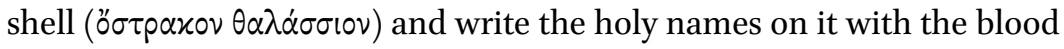

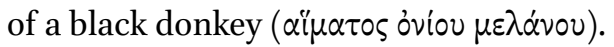

In sum, although the "blood of Typhon" is usually only another way of saying "blood of donkey," passages such as PGM LXI 61 prove that there were probably other substances that could also be called "blood of Typhon." In fact, the blood of donkey (that it is to say, the "blood of Typhon") could be replaced by minium in the ritual, as the last example demonstrates. This makes this pigment a good candidate for resolving the damage gloss of PGM LXI 61. Whether the minium could also have been called "blood of donkey" will be discussed in a moment.

al-aḥbār (13th century) by Muhammad Ibn Maymūn al-Marrākušī al-Ḥimyarī; Tuhaf al-hawāṣs fít turaf al-hawāṣṣ (d. 1307) by Abū Bakr Muhammad al-Qalalūsī. See an Italian translation of the recipes in Sara Fani, Le arti del libro secondo le fonti arabe originali. I ricettari arabi per la fabbricazione di inchiostri (sec. IX-XIII): loro importanza per una corretta valutazione e conservazione del patrimonio manoscritto, PhD Diss. (Naples: University of Naples, 2013), p. 43 R IV = p. 114 M ب̣ IV 2.d = p. 142 Q I.18; p. 106 м ب̣ III 4. On the scientific identification of the anemone see also ibid., p. 218. See also Sara Fani's chapter in this volume "The Literary Dimension and Life of Arabic Treatises on Ink Making."

61 Recipes are texts of fluid tradition and their comparison involves scholars analysing three aspects to determine a link between the different versions of a text: aim, procedure and core ingredients. See Lucia Raggetti, 'Tsā ibn 'Alì's Book on the Useful Properties of Animal Parts. Edition, translation and study of a fluid tradition (Berlin: De Gruyter, 2018). In this perspective, the parallel between the two procedures is clear: the typology of both spells is the same - binding spells - and both must be written on a seashell using an ink that contains a component associated with Typhon. 


\section{The Decknamen}

If one had to choose a text that best exemplifies the caution needed by scholars when approaching magical substances, it would be the aforementioned list of PGM XII (ll. 4O7-435). This list, which itemizes more than 40 names supposedly used to encode mineral and vegetal substances, is introduced as follows (ll. 400-407):

Interpretations from the translations of the temples employed by the

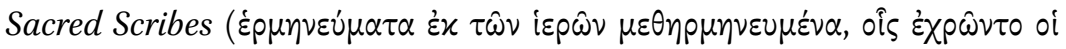

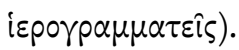

Because of the curiosity of the masses, they (i.e. the Sacred Scribes) inscribed ( $\dot{\varepsilon} \pi \dot{\varepsilon} \gamma \alpha \psi \alpha \nu)$ the names of the herbs and other things they employed on the statues of the gods, ${ }^{62}$ so that, when interested in these matters, they (i.e. the masses) could not inquire about ( $\pi \varepsilon p ı \varepsilon p \gamma \alpha \dot{\zeta} \omega \nu \tau \tau \alpha$ ) any of them as a result of the error (i.e. the misunderstanding resulting

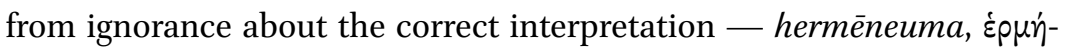
$\nu \varepsilon v \mu \alpha$ ). We, however, have collected the solutions (i.e. to the names of the herbs and other things used by the Sacred Scribes) from many copies of these texts ( $\alpha \nu \tau i \gamma p \alpha \dot{\alpha} \omega \nu)$, all of which are secret.

The list that follows enumerates thirteen substances named "blood of $x$ ":

\begin{tabular}{|c|c|c|}
\hline 409 & $\alpha i \mu \alpha$ ö $\varphi[\varepsilon] \omega \varsigma \cdot \alpha i \mu \alpha \tau i \tau \eta \varsigma \lambda i \theta \circ \varsigma$ & Snake blood: hematite stone \\
\hline 411 & 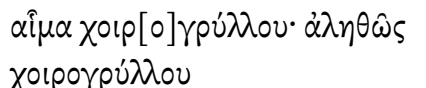 & Blood of hyrax; truly of hyrax \\
\hline 414 & 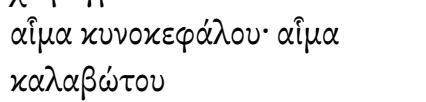 & Blood of baboon: blood of lizard \\
\hline 416 & $\alpha i \mu \alpha{ }^{\prime} H \varphi \alpha i \sigma \tau o v \cdot \alpha \rho \tau \tau \varepsilon \mu \sigma^{\prime} \alpha$ & Blood of Hephaistos: wormwood \\
\hline 9-22 & 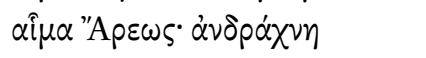 & Blood of Ares: purslane \\
\hline & $\alpha i \mu \alpha \partial \dot{\partial} \theta \alpha \lambda \mu \circ \hat{v} \cdot \alpha \kappa \alpha \kappa \alpha \lambda \lambda i \delta \alpha$ & Blood of an eye: tamarisk \\
\hline & $\alpha i \mu \alpha \dot{\alpha}^{\prime} \ddot{\omega} \mu 0 v \cdot \ddot{\alpha} x \alpha \nu \theta 1 \varsigma$ & Blood from a shoulder: bear's breach \\
\hline & $\dot{\alpha} \pi^{\prime} \dot{\partial} \sigma \varphi v^{\prime} \circ \varsigma^{\prime} \alpha \nu \theta \varepsilon \dot{\varepsilon} \mu \nu \nu$ & From the loins: chamomile \\
\hline
\end{tabular}

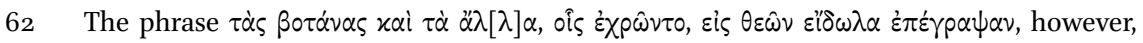
could be interpreted also as "they ascribed (i.e. assigned) the names of the herbs and other things they employed to the figures of the gods," see Miriam Blanco Cesteros "Los Hermeneumata de PGM/PDM XII (=GEMF 15): la Dreckapotheke mágica a examen" in Cuadernos de Filología Clásica. Estudios Griegos e Indoeuropeos 2020, 30:169-170. 


$$
\begin{aligned}
& 426 \quad \text { 'E } \sigma \tau i \alpha \varsigma \alpha \hat{i} \mu \alpha \cdot \alpha \nu \theta \varepsilon \dot{\varepsilon} \mu 10 \nu \\
& 428 \quad \alpha i \mu \alpha \chi \eta \nu \alpha \lambda \omega^{\prime} \pi \varepsilon \kappa \circ \varsigma^{\circ} \gamma \alpha \dot{\lambda} \alpha \alpha
\end{aligned}
$$

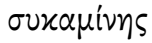

$$
\begin{aligned}
& 431 \quad \alpha i \mu \alpha \text { Kpóvov } x \varepsilon \delta \rho i ́ \alpha s
\end{aligned}
$$

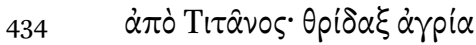

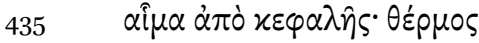

Blood of Hestia: chamomile

Blood of a goose: a mulberry tree's 'milk'

Kronos' blood: of cedar (resin of cedar?)

Of Titan: wild lettuce

Blood from a head: lupine

According to the introduction of this text, then, the substances itemized in this list were employed by the Egyptian Sacred Scribes (hierogrammateis,

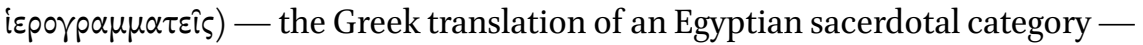
who encoded their names to conceal their true nature to the uninitiated. The fact that these supposedly code names were inscribed in the temples by the priests leads us to the Egyptian Temple of Dendera. In this holy compound, there is a chamber called the "Goldsmiths' workshop," a ritual and artisanal space where the effigies of the gods were first produced and later consecrated. Philippe Derchain identified several inscriptions on the chamber walls, probably copied from treatises dealing with the administrative and practical operations of this workshop. ${ }^{63}$ One of these texts ${ }^{64}$ is a list of equivalences between the names of several materials and the actual nature of these substances. This passage was likely extrapolated from a treatise about the production of statues. Thus, we have archaeological evidence of the actual existence of inscriptions like those mentioned by the texts of $P G M$ XII. According to Derchain, ${ }^{65}$ however, Dendera's equivalences seem to be glosses of archaic or obsolete terminology, rather than code names. This is, precisely, the conclusion of Jacco Dieleman regarding the list of $P G M$ XII: the names of the left column seems to be botanical names employed by Egyptian priests (above all physicians, as some medical texts prove) for which the right column provides a Greek identification. Therefore, this list might not be a list of code names, but a glossary of botanical terminology in two different languages. ${ }^{66}$

Either way, PGM XII list, motivated by secrecy or otherwise, illustrates three types of names depending on the provenance of the substance: names associated with an animal (like "snake's blood" and "donkey's blood"); with a god (such as the already analysed "Typhon's blood"); or with a body part (regarding

63 Philippe Derchain, "L'Atelier des Orfèvres à Dendara et les origines de l'Alchimie," in Chronique d'Égypte, 199o, vol. 65, n. 129: 219-242.

64 For the complete text, see Derchain, L'Atelier (cit. in the previous note), p. 235, text No. II.b.

65 Derchain, L'Atelier (cit. note 63), p. 223.

66 Jacco Dieleman, Priests, Tongues, and Rites: The London-Leiden Magical Manuscripts and Translation in Egyptian Ritual, 100-30o CE. (Leiden: Brill, 2005), pp. 185-203. This hypothesis has been recently ratified in Blanco Cesteros, Los Hermeneumata (cit. note 62). 
inks, the "blood of the hand" is used, e.g. in PGM IV 79). This list is also interesting because, apart from supporting the idea that actual blood was used to write in Greco-Egyptian magic, some of these alleged Decknamen can be identified with substances mentioned in other magical texts. It is the case of the "blood of baboon," indicated as a writing medium in PGM XIII 315. Although, according to the list, it would be blood of lizard, Lynn R. LiDonnici has convincingly demonstrated, through comparison with other $P G M$ passages in which baboon's materia magica is required, that the term kynokephalos ("baboon") in

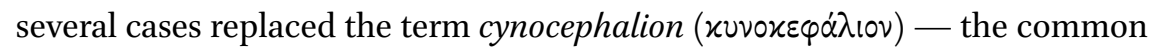
name of a plant. ${ }^{67} \mathrm{Her}$ conclusions, thus, require us to be cautious regarding the equivalence given by the list, which could be inaccurate, like in the case of the snake's blood. In any case, it is an additional piece of evidence that several mineral or vegetable substances - not necessarily for chromatic reasons were referred to as blood in magical texts. ${ }^{68}$

\section{Re-thinking the "Blood" of the Red Inks in Magical Texts}

We can now analyse one last set of inks. They are mentioned in the same recipe, which indicates that the magical practitioner should write on three different materials, each time using a particular ink:

Write on it [i.e. the hide] with blood of the heart of a slaughtered donkey

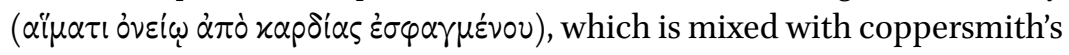
soot ( $\left.\alpha i \theta \dot{\alpha} \lambda \eta \chi \alpha \lambda x \varepsilon^{\prime} \omega \varsigma\right)$. The leaf of flax has to be inscribed with falcon blood ( $\alpha i \mu \alpha \tau\llcorner$ i $\varepsilon p \alpha x \varepsilon i \omega)$, which is mixed with goldsmith's soot ( $\alpha i \theta \dot{\alpha} \lambda \eta \chi p \nu$ -

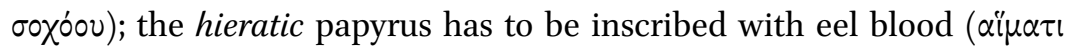
$\dot{\varepsilon} \nu \chi \dot{\varepsilon} \lambda \varepsilon \omega \varsigma)$, which is mixed with acacia ( $\left.\dot{\alpha} x \alpha x^{\prime} \alpha\right)$.

$P G M$ IV 2093-2097

There is, thus, a first ink [INK A] made with blood of donkey and "coppersmith's soot;" IN K B is made with the blood of falcon and "goldsmith's soot" and

67 Lynn R. LiDonnici, "Beans, Fleawort, and the Blood of a Hamadryas Baboon: Recipe Ingredients in Greco-Roman Magical Materials," in Magic and Ritual in the Ancient World, edited by Paul Mirecky and Marvin Meyer (Leiden: Brill, 2002), pp. 359-377, especially pp. 371-372. Note that this replacement is very similar to what has happened with drakontion/ophis in the case of the snake's blood. In fact, in her article, LiDonnaci evinces phenomena very similar to those pointed out in the present study.

68 See, e.g. the chamomile (called "blood of Hestia"). As for the name of the wild lettuce ("blood of Titan"), see Blanco Cesteros, Los Hermeneumata (cit. note 62), pp. 162-165. 
INK C, with blood of eel and acacia. As is clear, the ingredients of these three inks immediately recall the first ink analysed in this paper, i.e. the ink made

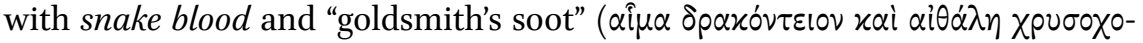
ixท́) (henceforth INK D). The resemblance does not seem accidental, given that INK D appears in the same papyrus, $P G M$ IV.

With respect to the substances employed in these inks, only the snake blood and the acacia can be identified with some certainty. The latter probably refers

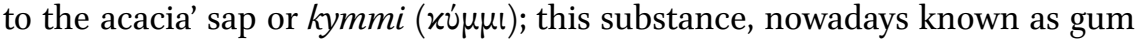
arabic, was commonly employed as a binder in the production of inks. ${ }^{69}$ It is noteworthy, however, that the recipe refers to a well-known substance not by its customary name, but using an elusive term. This recalls the probable identification of the "goldsmith's soot" - INKS B and D - as simple gold (see above, §3). Can we assume, by analogy, that the "coppersmith's soot" of INK A is simply copper? It is difficult to say with certainty, but there is some indication that we should not interpret the name of these substances literally. Firstly, the "blood of falcon" stands out because it is the only mention in the Greek and Demotic magical papyri of its use as ingredient. There were, in fact, ritual reasons not to use the blood of this animal, which was identified with the solar god Horus and was, therefore, one of Egypt's most sacred birds. The spilling of falcon blood was avoided and forbidden, even in magic: its blood sacrifice is denounced as an impious action in PGM IV $2593(=2656)$ and, at the moment when the sacrifice of a falcon is required (PGM I 1-15), this is carried out by "deification," i.e. by drowning the animal without spilling its blood. It is unlikely, therefore, that actual blood of falcon was used as ink by Greco-Egyptian magicians..$^{70}$ The same goes for the "blood of eel," another unique occurrence in the Greek and Demotic magical papyri, as this animal was also sacred in Egypt. ${ }^{71}$ Since the snake blood of INK D was a resin, it could also be the case that these other "bloods" were vegetable or mineral substances. However, in the absence of a clear referent, their nature remains obscure. Any attempt to identify them is complicated by the complex net of sympathetic associations of Greco-Egyptian magic - without forgetting eventual alterations that occurred in the textual transmission of the recipes, as well as the

69 See Christiansen et al., Chemical characterization (cit. note 57), p. 209.

70 Recent research on this substance confirms this assumption and demonstrates that hier-

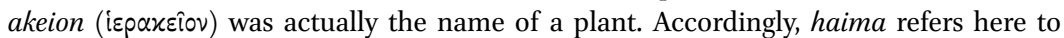
another sap; see Blanco Cesteros, Los Hermeneumata (cit. note 62), pp. 162-165.

71 See, e.g. Hdt., 2.72.3. The sacred nature of this animal has been confirmed by the discovery of mummified eels, placed in small bronze cases, see Karol Myśliwiec, The Twilight of Ancient Egypt: First Millennium B.C.E. (Ithaca-London: Cornell University Press 20oo), p. 9 . 
possibility of a problematic translation of substances' names from other languages. Many red pigments - minium, cinnabar, hematite (red ochre), resins, etc. - were used to produce red inks, as indicated by both ancient sources and modern chemical analysis of ancient inks. ${ }^{72}$ If this were the case, the "blood of the heart of a slaughtered donkey" (INK B) could be minium. The fact that the blood has to come from "the heart of a slaughtered animal" should not be considered as an argument in favour of its interpretations as actual blood. It could be a later specification introduced by a compiler and/or based on a literal interpretation of the substance name. The loss of awareness about the polysemy of given terms resulted in, for example, Akkadian common botanical names like "dog tongue" or "lion fat" being interpreted as actual animal substances in later herbal treatises and pharmacological traditions. ${ }^{73}$

If so, an ink made with minium and copper would have had a beautiful, metallic red colour like the ink made from the resin called snake blood and gold (IN K D). The alchemical tradition offers recipes of a couple more inks with this finishing touch: in addition to the aforementioned $M C 45$ (see above, §3), the ink from $M C 34$ is based on minium and gold powder, while $M C 40$ uses ochre and mercury for a similar preparation.

Concluding Remarks: "Blood" as a Polysemic Reality in Magic

The magical pantry is characterized by the peculiarity and oddity of its ingredients, something also attested to in the composition of the inks described in Greco-Egyptian magical papyri. In particular, the preference for red apparently made blood the most common ingredient for writing in this ritual field. However, the use of blood as (or in) ink was not a phenomenon restricted to magic, and not all apparent "bloods" mentioned in magical inks referred to actual blood. Some, in fact, conceal the name of other substances, encoded by the transmission or by the ritual practitioners. As a result, when properly analysed, some magical inks are no different from those referred to by other sources.

The point of this study has not been to decipher the Decknamen of the Greek Magical papyri, but rather to raise awareness about the problematic polysemy

\footnotetext{
72 See Christiansen et al., Chemical characterization (cit. note 57), passim.

73 Erica Reiner, Astral Magic in Babylonia (Philadelphia:The American Philosophical Society, 1995), pp. 32-33; an extended analysis of this topic in Maddalena Rumor, Babylonian Pharmacology in Graeco-Roman Dreckapotheke. With an Edition of Uruanna III 1-143 (138), PhD Diss. (Berlin: Freie Universität Berlin, 2015).
} 
of magical ingredients and the multiple linguistic, ritual and textual paths that lead to this phenomenon. The real nature of substances is hidden in diverse and not always intentional ways. The literal reading, for example, of botanical names by insufficiently trained scribes introduced alterations (misinterpretations, inferences, lexical variants, etc.) in the textual transmission that blurred the actual nature of these substances. Although not all the names for magical substances have a dual meaning, scholars working with magical recipes must be aware of the potential polysemy of substances and not assume that ingredients should be interpreted literally, especially those belonging to the magical Dreckapotheke. ${ }^{74}$

The different "bloody" ingredients examined in this study have also served to highlight the method for approaching those substances involved in magical rituals and procedures. Considered individually, the hidden polysemy would have been barely noticeable; only a comparative study (that included magical and non-magical texts) yields hints about the non-literal value of these names. The ritual context itself is a valuable asset in the recognition of polysemic terms. The interpretation of many of these terms, however, remains open as a result of the dynamic textual phenomena and the complex connections of sympathies and antipathies that underlie Greco-Egyptian magic. In any case, the more we understand this ritual field and its sources, the better we are able to decode them.

74 The list of PGM XII, for example, is full of "bloods," "fats," "excrements," and "semen." 